\title{
Genetic background of nonmutant Piebald-Virol- Glaxo rats does not influence nephronophthisis phenotypes
}

This article was published in the following Dove Press journal: International Journal of Nephrology and Renovascular Disease 16 February 2013

Number of times this article has been viewed

\author{
Jada Pasquale Yengkopiong \\ Joseph Daniel Wani Lako \\ John Garang Memorial University \\ of Science and Technology, Faculty \\ of Science and Technology, Bor, Jonglei \\ State, Republic of South Sudan
}

Background: Nephronophthisis (NPHP), which affects multiple organs, is a hereditary cystic kidney disease (CKD), characterized by interstitial fibrosis and numerous fluid-filled cysts in the kidneys. It is caused by mutations in NPHP genes, which encode for ciliary proteins known as nephrocystins. The disorder affects many people across the world and leads to end-stage renal disease. The aim of this study was to determine if the genetic background of the nonmutant female Piebald-Virol-Glaxo (PVG/Seac ${ }^{-/}$) rat influences phenotypic inheritance of NPHP from mutant male Lewis polycystic kidney rats.

Methods: Mating experiments were performed between mutant Lewis polycystic kidney male rats with CKD and nonmutant PVG and Wistar Kyoto female rats without cystic kidney disease to raise second filial and backcross 1 progeny, respectively. Rats that developed cystic kidneys were identified. Systolic blood pressure was determined in each rat at 12 weeks of age using the tail and cuff method. After euthanasia, blood samples were collected and chemistry was determined. Histological examination of the kidneys, pancreas, and liver of rats with and without cystic kidney disease was performed.

Results: It was established that the genetic background of nonmutant female PVG rats did not influence the phenotypic inheritance of the CKD from mutant male Lewis polycystic kidney rats. The disease arose as a result of a recessive mutation in a single gene (second filial generation, $\mathrm{CKD}=13$, non-CKD $=39, \chi^{2}=0.00, P \geq 0.97$; backcross 1 generation, $\mathrm{CKD}=67$, non-CKD $\left.=72, \chi^{2}=0.18, P>0.05\right)$ and inherited as NPHP. The rats with CKD developed larger fluid-filled cystic kidneys, higher systolic blood pressure, and anemia, but there were no extrarenal cysts and disease did not lead to early pup mortality.

Conclusion: The genetic background of the nonmutant PVG rats does not influence the genetic and phenotypic inheritance of CKD from mutant Lewis polycystic kidney rats. A single recessive mutation incapacitated the gene, which relaxed its functional constraints, and led to formation of multiple cysts in the kidneys of the homozygous mutant rats.

Keywords: recessive mutation, cystic kidney disease, nephronophthisis, systolic blood pressure, anemia

\section{Introduction}

A few years ago, identification of the genetic basis of inherited human diseases, such as cystic kidney disease (CKD), was a painstaking procedure. Initially, it required many years of hard work to identify families with the disease for linkage analysis. This was followed by endless fine mapping of the loci associated with the disease and sequencing the candidate genes until the causative mutation was identified. ${ }^{1}$ Once the mutation was identified, there was also the need to understand the biological pathway that led to the development of the disease. However, nowadays the use of animal models for
Correspondence: Jada Pasquale Yengkopiong John Garang Memorial University of Science and Technology, Faculty of Science and Technology, Bor, Jonglei State, Republic of South Sudan Tel +2II 955621320

Email jadalojuka@yahoo.com.au 
characterization of complex human diseases has progressed our understanding of inherited human diseases, allowing us new insights into the underlying biology of these disorders. ${ }^{2}$ The development of methods for rapid characterization of the genes responsible for these diseases has facilitated our understanding of the functions of these genes and how mutations in the genes interrupt biological pathways, leading to development of disease. ${ }^{3}$ Understanding the biological pathways of such diseases will facilitate progress in the development of therapeutic interventions to cure and/or prevent them.

In a recent study of autosomal recessive polycystic kidney disease (ARPKD) in the Lewis polycystic kidney (LPK) rat, the quantitative trait locus responsible for the disease phenotype was mapped to chromosome 10q21-q26. ${ }^{4}$ The quantitative trait locus was large and contained many candidate genes, some of which are important in signal transduction, cell growth, cell proliferation, and cell differentiation.,6 Mutations in some of these genes were associated with unregulated cell proliferation and cancer. ${ }^{7-9}$ After mapping of the quantitative trait locus, a fine mapping of the entire rat chromosome 10 was carried out and the quantitative trait locus was then refined to a region on rat chromosome $10 \mathrm{q} 25 .{ }^{10}$

Targeted genome capture and next-generation sequencing of the defined approximately $1.6 \mathrm{Mbp}$ region on chromosome 10q25, which harbors the lpk mutation, was performed. A novel mutation, R650C substitution, located within a G[QRC]LG repeat motif, was identified as the cause of ARPKD in the LPK rats. This region localizes to a conserved domain of the regulator of chromosome condensation 1 (RCC1) in the never in mitosis A (NIMA)related kinase 8 (Nek8) gene. ${ }^{10}$ In previous studies, mutations in the Nek 8 gene were associated with development of nephronophthisis (NPHP) in human and other animal species. ${ }^{11-13}$ As a result, the ARPKD in the LPK rats is now considered a NPHP.

Studies show that NPHP is a chronic interstitial nephropathy, which involves multiple organ systems, and causes cystic kidneys, retinitis pigmentosa, ${ }^{14}$ cerebellar vermis hypoplasia, and liver fibrosis. ${ }^{11,15-18}$ NPHP also leads to endstage renal disease. ${ }^{19-22}$ Through positional cloning, many of the causative mutations in NPHP have been mapped to genes involved in centrosome and cilia function. ${ }^{23}$ Recently, positional cloning of the nine genes (NPHP1-NPHP9), and functional characterization of their encoded proteins (nephrocystins), have contributed to a unifying theory that defines cystic kidney diseases as ciliopathies. ${ }^{16}$ This theory is based on the finding that all the proteins of the mutated genes in CKD, in human and animal models, are expressed in the primary cilia or centrosomes of renal epithelial cells. ${ }^{21}$

Many of the ciliopathies described display multiple organ involvement, with the kidneys and retina being the most commonly affected. ${ }^{23}$ Furthermore, it was established that primary cilia are sensory organelles that connect mechanosensory, visual, and other stimuli to mechanisms of epithelial cell polarity and cell cycle control. ${ }^{24,25}$ Because of this, cilia are central to perception of the physical environment through detection of diverse extracellular signals, such as growth factors, chemicals, light, and fluid flow. ${ }^{19}$ Recently, research has established that mutations in Nek8 genes, which are involved in the development of NPHP, also cause defects in mechanisms that involve noncanonical Wnt signaling and the sonic hedgehog-signaling pathways, ${ }^{23,24,26,27}$ resulting in defects of planar cell polarity and tissue maintenance. ${ }^{28}$ These findings imply that mutations in NPHP involve many organs in disease presentation, resulting in retinal degeneration, cerebellar hypoplasia, liver fibrosis, situs inversus, and mental retardation. ${ }^{16}$

Since the emergence of ARPKD, many murine models have been studied to understand its causes and how it progresses. ${ }^{29-32}$ Of all the models, the polycystic kidney ( $p c k$ ) rat presents with phenotypes that resemble human CKD phenotypes..$^{33,34}$ In the current study, a spontaneous mutation in a colony of Lewis rats occurred at the Animal Resources Center of Western Australia, and this caused development of CKD, as previously described. ${ }^{4}$ Mating experiments between pups with CKD produced all progeny with CKD, and this colony is now referred to as the LPK rat., ${ }^{4,35}$ It is now confirmed that CKD in the LPK rat is an NPHP and the mutation has been located in the Nek8 gene. However, it is not understood why the disease does not involve multiple organs or cause early pup death.

Therefore, the aim of this study was to determine if the genetic background of Piebald-Virol-Glaxo (PVG/Seac ${ }^{-/}$) female rats influences genetic and phenotypic inheritance of NPHP from mutant male LPK rats. This is important because recent findings indicate that susceptibility to CKD in the mutant $p c k$ rat is attenuated by the genetic background of Fawn-Hooded hypertensive rats. ${ }^{36}$ Attenuation of genetic causes of a disease due to genetic alteration in the mutant rat implies that genetic modifier loci from the Fawn-Hooded hypertensive rat interfere with genetic expression of CKD.

\section{Materials and methods}

In this study, mutant male LPK rats were mated with nonmutant female PVG and Wistar Kyoto (WKY) rats to 
produce second filial and backcross 1 progeny, respectively. The progeny with cystic kidneys and those without cystic kidneys were identified. Systolic blood pressure and blood chemistry measurement and histological examination of the kidneys, liver, and pancreas was performed, as described in detail below. PVG rats, like WKY rats, were used in the study because both strains are genetically distant from LPK rats.

\section{Background}

A colony of Lewis (LEW/SsNArc $\left.{ }^{-/}\right)$rats spontaneously developed enlarged cystic kidneys at the Animal Resources Center of Western Australia. Mating experiments between male and female progeny with enlarged cystic kidneys produced $100 \%$ pups with bilaterally enlarged fluid-filled cystic kidneys. ${ }^{4,35}$ However, there were no extrarenal cysts and the disease did not cause pup death. This colony is now known as the Lewis polycystic kidney (LPK/SsNArc ${ }^{+++}$) rat.

\section{Mating experiments}

Three mutant male LPK/SsNArc ${ }^{+/+}$rats were mated with five nonmutant PVG/Seac ${ }^{--}$and seven Wistar Kyoto (WKY/ $\mathrm{NArc}^{--}$) female rats to produce first filial generations. Seven male and seven female rats from the heterozygote LPK/PVG F1 progeny were mated and produced 52 pups in the second filial generation. Fifteen female rats from the heterozygote LPK/WKY F1 progeny were mated with the three parent LPK male rats and produced 139 pups in the backcross 1 generation. All the animals were kept on a 12-hour light/ dark cycle and had free access to the same food and water. The experiments were performed in accordance with the guidelines of the animal ethics committees of Murdoch University (Murdoch, WA, Australia) and the Animal Resources Center of Western Australia. ${ }^{435}$

\section{Phenotypic trait analysis}

The progeny were earmarked and recorded and each was palpated once every week from immediately after birth until euthanasia to determine which rat had developed enlarged cystic kidneys. Enlarged kidneys were confirmed on euthanasia and the presence of cysts was established on histological examination of the kidneys. Systolic blood pressure was measured when the rats were 12 weeks old using the tail-cuff method (NIBP Controller, ADI Instruments, Castle Hill, Australia). Three measurements were taken, and the average measurement was used in statistical analysis. However, it has been decided that telemetry will be used in future studies to measure systolic blood pressure.., 35

\section{Euthanasia}

The rats were euthanized using a carbon dioxide and oxygen gas mixture in proportions of 80:20, respectively. After euthanasia, the rats were weighed and their mass recorded in grams. Blood was removed by cardiac puncture into lithium-heparin tubes. The rats were opened on the ventral side along the linear alba and the kidneys and sections of liver and pancreas were removed. Each kidney was weighed and the mass was recorded, and the kidneys and sections of the liver and pancreas were fixed in $4 \%$ formaldehyde solution. ${ }^{4,35}$

\section{Packed cell volume}

Packed cell volume was determined in $2 \mathrm{~mL}$ blood samples at the Department of Pathology, Murdoch University, using the microhematocrit technique and a hemocentrifuge (Haeraeus Biofuge, Randox Laboratories Ltd, Crumlin, UK) according to the manufacturer's instructions, as previously described. ${ }^{4,35}$

\section{Blood chemistry}

Plasma total solid protein was estimated using ethylenediamine tetra-acetic acid and a refractometer (Randox Laboratories Ltd) according to the manufacturer's instructions. To $20 \mu \mathrm{L}$ of samples, blank and standard solution were added $1000 \mu \mathrm{L}$ of Pyrogallol red. This was mixed and incubated at $37^{\circ} \mathrm{C}$ for 5 minutes. The absorbance of the samples $\left(\mathrm{A}_{\text {sample }}\right)$ and the standard $\left(\mathrm{A}_{\text {standard }}\right)$ was measured against the reagent blank at a $600 \mathrm{~nm}$ wavelength using a spectrophotometer. The protein concentration was calculated as:

\section{Protein concentration $(\mathrm{g} / \mathrm{L})=\mathrm{A}_{\text {sample }} \times[$ standard $] / \mathrm{A}_{\text {standard }}$}

where [standard] is the concentration of the standard solution in $\mathrm{g} / \mathrm{L}, \mathrm{A}_{\text {sample }}$ is the absorbance of the sample, and $\mathrm{A}_{\text {standard }}$ is the absorbance of the standard solution.

Plasma creatinine was determined as follows: sodium hydroxide and picric acid were added to $20 \mu \mathrm{L}$ samples as per the instructions provided by the manufacturer (Randox Laboratories). Creatinine, in the presence of sodium hydroxide solution, reacts with picric acid to form a colored complex. The rate of formation of the complex was measured using a colorimetric method. Plasma urea was measured on a Randox Daytona and the reaction was catalyzed by urease enzyme (Randox Laboratories Ltd). The ammonia produced during the reaction combined with $\alpha$-oxoglutarate and hydrogenated nicotinamide adenine dinucleotide (NADH), in the presence of glutamate dehydrogenase, to yield glutamate and $\mathrm{NAD}^{+}$. 
The $\mathrm{NAD}^{+}$produced was measured in $\mu \mathrm{mol} / \mathrm{L}$ using an ultraviolet method, as previously described. ${ }^{4}$

\section{Histological examination of tissues}

Histological examination of the sections of kidney, liver, and pancreas was carried out at the Department of Histology, Murdoch University. The tissues were paraffin-embedded and sectioned ( $4 \mu \mathrm{m}$ thickness) using a microtome. The sections were fixed on glass slides, stained with hematoxylin and eosin, viewed by light microscopy, and the images were digitalized using a camera (Olympus, Perth, Australia), as described elsewhere. .,35 $^{4}$

\section{Statistical analysis}

Statistical analysis was carried out using the Statistical Package for Social Sciences version 16 (SPSS Inc, Chicago, IL, USA). Two-way analysis of variance and multiple comparison tests with post hoc analysis of the combined male and female data sets were carried out and statistical significance was considered at $P<0.05$, unless otherwise stated.

\section{Results}

Segregation ratios showed inheritance of a recessive mutation in a single gene (Table 1). The cysts were only found in the kidneys of CKD rats (Figure 1). Blood chemistry (Table 2) showed that the cysts in the kidneys led to deterioration of kidney function. As a result, the kidneys were unable to regulate the concentrations of total solid protein $(\mathrm{g} / \mathrm{L})$, pseudouridine $(\mathrm{mmol} / \mathrm{L})$, and plasma creatinine $(\mathrm{mmol} / \mathrm{L})$. However, there were no significant differences in concentrations in the nonmutant or mutant rats between second filial and backcross 1 progeny. The percentage kidney/body weight did not vary significantly in either the nonmutant or mutant rats in either the second filial or backcross 1 progeny, which suggests that there are no modifier loci in the background strain with significant effects on the disease phenotypes. The increase in systolic blood pressure and decrease in packed cell volume strongly suggest that kidney deterioration due to development of cysts caused the changes in these phenotypic traits. The effect of genetic mutation (Figure 2) at RCC1 on the Nek8 gene located

Table I Number of rats with and without cystic kidneys and Chi-square statistics

\begin{tabular}{lllllll}
\hline Generation & Progeny & E & O & Ratio & $\chi^{2}$ & $P$-value \\
\hline F2 & 52 & 13 & 13 & $1: 03$ & 0 & $\geq 0.97$ \\
BCI & 139 & 70 & 67 & $1: 01$ & 0.2 & $>0.05$ \\
\hline
\end{tabular}

Abbreviations: F2, second filial generation; $\mathrm{BCl}$, backcross I generation; $E$, expected number of rats with CKD; O, observed number of rats with CKD; $\chi^{2}$, Chi-square values; CKD, cystic kidney disease.

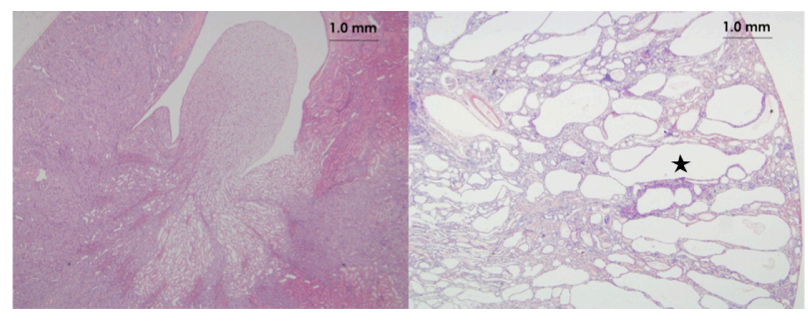

Figure I Microscopic anatomy of kidneys from a backcross I rat.

Notes: The kidney on the left has not developed cysts, while the kidney on the right has developed cysts. The star shows the cysts, which coalesce to form larger cysts. Magnification 400x.

in chromosome $10 \mathrm{q} 25$ led to a series of interconnected events, each being a consequence of the occurrence of the first event.

\section{Discussion}

This study demonstrates that the genetic background of female PVG rats does not influence the expression of NPHP phenotypes. This discovery contradicts previous findings where an epistatic interaction between alleles of the modifying background and environmental factors attenuated CKD phenotypes in other mutant murine models. ${ }^{37-40}$ Percentage kidney/body weight and other phenotypes are not significantly different in the mutant second filial and backcross 1 progeny. This confirms that there are no modifier loci in the background strain to influence the disease phenotypes.

Unlike the known forms of NPHP, which are characterized by multiple organ involvement, ${ }^{41,42}$ the cysts in this model are consistently localized to the kidneys only. The segregation ratios of $3: 1$ in the second filial and $1: 1$ in the backcross 1 progeny $(P>0.05)$ strongly support the ratios for inheritance of traits controlled by a recessive trait in single gene. ${ }^{4,43,44}$ These ratios also show that there are no genetic modifier loci in the nonmutant background strains with a strong epistatic interaction capable of modulating the effects of the causative gene and altering expression of the disease phenotypes. Therefore, this finding highlights how genetic mutations in different genetic loci lead to development of CKDs, most of which present with similar phenotypes. This finding also suggests that there must be at least one converging point in the disease pathways shared by mutations in genes that leads to development of different types of ciliopathy. This converging point, if identified, will result in identification of therapeutic intervention strategies which may inhibit progression of ciliopathies.

Most CKDs, including polycystic kidney disease, ${ }^{45}$ Joubert syndrome, ${ }^{42}$ Senior-Løken syndrome, ${ }^{46}$ and NPHP ${ }^{16,21}$ are disorders that are considered in the spectrum of ciliopathies. ${ }^{1,47}$ The phenotypic expression of these diseases is influenced by 
Table 2 Phenotypes of $\mathrm{F} 2$ and $\mathrm{BCl}$ generations showing mean values for TSP, PU, PC, PCV, and \%RK/BW in non-CKD and CKD rats

\begin{tabular}{|c|c|c|c|c|}
\hline & \multicolumn{2}{|c|}{ F2 Generation ${ }^{\alpha}$} & \multicolumn{2}{|c|}{ BCI Generation ${ }^{\alpha}$} \\
\hline & $\begin{array}{l}\text { non-CKD } \\
(n=39)\end{array}$ & $\begin{array}{l}\text { CKD } \\
(n=13)\end{array}$ & $\begin{array}{l}\text { non-CKD } \\
(n=72)\end{array}$ & $\begin{array}{l}\text { CKD } \\
(n=67)\end{array}$ \\
\hline TSP (g/L) & $68.54 \pm 0.43$ & $62.71 \pm 0.96 *$ & $69.02 \pm 0.63$ & $63.00 \pm 0.7 I^{*}$ \\
\hline $\mathrm{PU}(\mathrm{mmol} / \mathrm{L})$ & $05.66 \pm 0.13$ & $09.10 \pm 0.70^{* *}$ & $05.76 \pm 0.15$ & $10.56 \pm 0.49 * *$ \\
\hline $\mathrm{PC}(\mathrm{mmol} / \mathrm{L})$ & $61.63 \pm 0.75$ & $66.24 \pm 2.23^{*}$ & $59.64 \pm 0.92$ & $66.41 \pm 1.63^{*}$ \\
\hline PCV (L/L) & $0.49 \pm 0.01$ & $0.38 \pm 0.02 *$ & $0.50 \pm 0.01$ & $0.40 \pm 0.01 *$ \\
\hline$\% \mathrm{RK} / \mathrm{BW}$ & $0.80 \pm 0.02$ & $4.57 \pm 0.44^{* * *}$ & $0.81 \pm 0.02$ & $4.55 \pm 0.28 * * *$ \\
\hline $\mathrm{SBP}(\mathrm{mmHg})$ & $116.0 \pm 1.50$ & $165.0 \pm 3.50 * * *$ & $116.0 \pm 1.70$ & $167.0 \pm 2.90$ *** \\
\hline
\end{tabular}

Notes: Data are presented as the mean \pm standard error of the mean, $* P<0.0 \mathrm{I}$, $* * p<0.00 \mathrm{I}, * * * P<0.000 \mathrm{I}$. $\mathrm{n}$, number of rats in each group; $\alpha$, comparison of parameters of non-CKD and CKD rats.

Abbreviations: CKD, cystic kidney disease; TSP, total solid protein; PU, plasma urea; PC, plasma creatinine; PCV, packed cell volume; SBP, systolic blood pressure; \%RK/BW, percentage relative kidney/body weight; $\mathrm{F} 2$, second filial generation; $\mathrm{BCl}$, backcross I generation.

the genetic background of nonmutant parents. ${ }^{36,38,48}$ However, in this study, it is established that the genetic background of the female PVG rat does not influence the phenotypic expression of NPHP. This finding is consistent with earlier findings that nonmutant Brown-Norway and WKY female rats do not significantly influence expression of the disease. ${ }^{4}$

In both the previous study ${ }^{4}$ and in the current study, the heterozygous first filial populations did not develop NPHP. Loss of expression of disease phenotypes in the first filial progeny suggests that the $l p k$ locus was recessive and it must be a homozygote to show its effects. Consistent with this, a recessive mutation in a single gene was identified as the cause of ARPKD 4 and the mutated gene was later identified as Nek8. ${ }^{10}$ Previously, a mechanism leading to development of NPHP was proposed. ${ }^{13}$ However, this mechanism leads to multiple organ involvement, and did not occur in this rat model. The lack of multiple organ involvement makes us wonder whether mutations in the Nek 8 genes really have any link with mutations in $P k h d-1$, and whether or not the biological disease pathways share at least one common pathway when mutations occur in Nek8 or Pkhd-1 genes. Enlargement of the kidneys resulted in increased systolic blood pressure, deterioration of kidney function, development of anemia, and loss of kidney homeostatic function in all the rats with cystic kidneys. However, unlike other rat models studied previously, ${ }^{29,49,50}$ disease in this model did not cause early pup death.

In human studies, infants with NPHP suffer from pulmonary hypoplasia and most die early in life. ${ }^{51}$ In the present study, there were no early pup deaths, indicating that the mutant progeny did not suffer from pulmonary hypoplasia. This finding also suggests that the mutation in the Nek8 gene may not share the same biological pathway as other mutations on the same gene or Pkhd-1 gene. Furthermore, patients with ARPKD or NPHP develop extrarenal cysts in the liver, spleen, pancreas, and other extrarenal organs. ${ }^{47}$ Although ciliopathies are characterized by intrafamilial and interfamilial phenotypic variability, which arise as a result

Rat chromosome 10

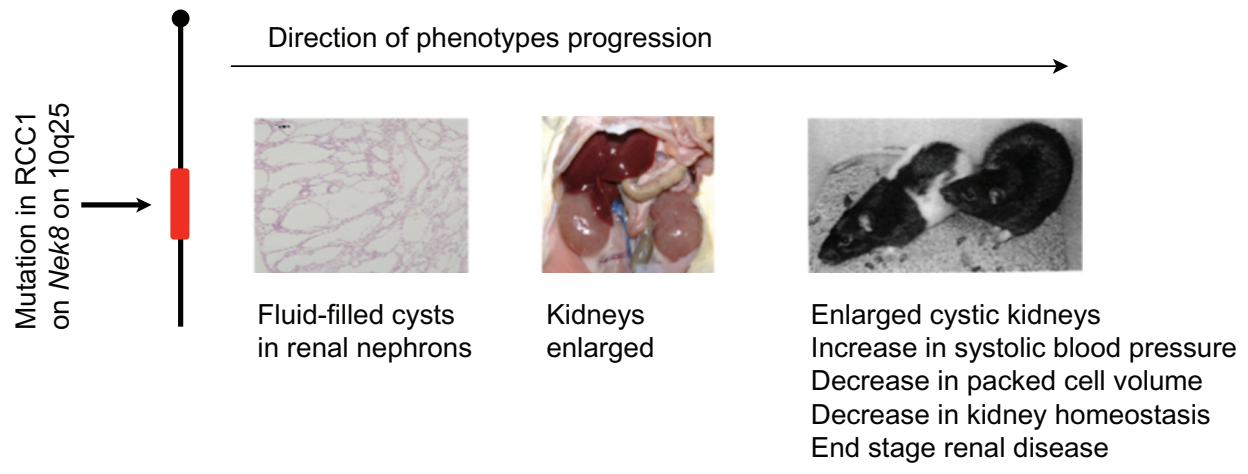

Figure 2 Domino effect resulting from mutation in the Nek8 gene.

Notes: Mutation in regulator of chromosome condensation I on the Nek8 gene located on rat chromosome 10q25 incapacitated the gene and led to relaxation of the functional constraints. This led to formation of cysts in the renal nephrons. Fluids accumulated in the cysts, which led to end-stage renal disease. 
of mutations in the genes necessary for functioning of the primary cilia in different organs, and therefore give rise to dramatically different phenotypes, ${ }^{52}$ this alone does not explain the markedly different clinical outcomes in this study. These different clinical outcomes will cause a dramatic shift in the clinical management options for NPHP.

All the rats with cystic kidneys developed higher systolic blood pressure than their age-matched counterparts without cystic kidneys, and this is a common feature of every patient and animal model with cystic kidneys. ${ }^{53}$ Increased systolic blood pressure precedes end-stage renal disease. This is similar to the development of higher systolic blood pressure in humans with cystic kidneys, as previously described. ${ }^{54}$ However, the mechanism of development of higher systolic blood pressure because of NPHP is not well understood. However, stimulation of the renin-angiotensin-aldosterone system and increased sympathetic activity are suggested to influence changes in systolic blood pressure in all individuals with cystic kidneys. ${ }^{55}$

In clinical studies, measurement of plasma protein, urea, creatinine, and packed cell volume in patients with kidney disease is important to be able to predict the effects of the disease on homeostatic function of the kidney and, therefore, development of anemia. ${ }^{56,57}$ It is now established that the cysts have negatively impacted on the functions of the nephrons and the associated renal cells. Previously, anemia was found to be a result of reduction in red blood cell mass or hemoglobin concentration or both, but the reason for this was not clear. ${ }^{58}$ In this study, decreased packed cell volume was a consequence of deterioration of kidney function.

Therefore, this study provides irrefutable evidence that, unlike the reported cases of genetic modification of cystic kidneys in other models, ${ }^{38,40,48,59-61}$ the genetic background of the PVG rat does not influence the genetic and phenotypic inheritance of NPHP from the mutant LPK rat. Without doubt, this study validates earlier findings that a recessive mutation in a single gene is the cause of CKD in the LPK rat. The mutation was later localized to RCC1 on the Nek8 gene. ${ }^{10}$ This mutation incapacitated the gene and caused relaxation in functional constraints, with a "domino" effect. ${ }^{14}$ However, unlike other mutations on the same gene, which cause multiple organ defects, our study has consistently produced mutant rats with no extrarenal cysts and no early pup death.

We have shown that the genetic background of the PVG rat does not influence the phenotypic inheritance of CKD in this model. However, we are aware that some weak genotype-phenotype variations exist because of mutations at certain single genetic loci. Because of this, the nature and strength of mutational effects on protein function will continue to vary. This variation will only be understood when the disease pathways are identified. Therefore, a concerted effort should be made to identify the pathway involved in the pathogenesis of NPHP in this rat model. In this way, we will be able to identify therapeutic interventions to manage NPHP. Therefore, any attempt to address these limitations will be important in the clinical management of NPHP.

\section{Acknowledgments}

We would like to acknowledge and thank Dr Chandrika of the Animal Resources Center of Western Australia for breeding the rats used in this study. This research was funded by Murdoch University.

\section{Disclosure}

The authors report no conflicts of interest in this work.

\section{References}

1. Novarino G, Akizu N, Gleeson JG. Modeling human disease in humans: the ciliopathies. Cell. 2011;147(1):70-79.

2. Zaghloul NA, Katsanis N. Functional modules, mutational load and human genetic disease. Trends Genet. 2010;26(4):168-176.

3. Liu S, Lu W, Obara T, et al. A defect in a novel Nek-family kinase causes cystic kidney disease in the mouse and in zebrafish. Development. 2002;129(24):5839-5846.

4. Yengkopiong JP. Polycystic kidney disease gene in the Lewis polycystic kidney rat is mapped to chromosome 10q21-q26. Adv Genomics Genet. 2012;2:55-66.

5. Bourne HR, Sanders DA, McCormick F. The GTPase superfamily: a conserved switch for diverse cell functions. Nature. 1990;348(6297): 125-132.

6. Hoshino M, Yoshimori T, Nakamura S. Small GTPase proteins Rin and Rit Bind to PAR6 GTP-dependently and regulate cell transformation. J Biol Chem. 2005;280(24):22868-22874.

7. Margolis B, Skolnik EY. Activation of Ras by receptor tyrosine kinases. J Am Soc Nephrol. 1994;5(6):1288-1299.

8. Garbay C, Liu WQ, Vidal M, Roques BP. Inhibitors of Ras signal transduction as antitumor agents. Biochem Pharmacol. 2000;60(8): $1165-1169$.

9. Cowley BD Jr, Chadwick LJ, Grantham JJ, Calvet JP. Elevated protooncogene expression in polycystic kidneys of the C57BL/6J (cpk) mouse. J Am Soc Nephrol. 1991;1(8):1048-1053.

10. McCooke JK, Appels R, Barrero RA, et al. A novel mutation causing nephronophthisis in the Lewis polycystic kidney rat localises to a conserved RCC1 domain in Nek8. BMC Genomics. 2012;13(1):393.

11. Bollee G, Fakhouri F, Karras A, et al. Nephronophthisis related to homozygous NPHP1 gene deletion as a cause of chronic renal failure in adults. Nephrol Dial Transplant. 2006;21(9):2660-2663.

12. Tory K, Rousset-Rouviere C, Gubler MC, et al. Mutations of NPHP2 and NPHP3 in infantile nephronophthisis. Kidney Int. 2009;75(8):839-847.

13. Zalli D, Bayliss R, Fry AM. The Nek8 protein kinase, mutated in the human cystic kidney disease nephronophthisis, is both activated and degraded during ciliogenesis. Hum Mol Genet. 2012;21(5):1155-1171.

14. Murga-Zamalloa CA, Desai NJ, Hildebrandt F, Khanna H. Interaction of ciliary disease protein retinitis pigmentosa GTPase regulator with nephronophthisis-associated proteins in mammalian retinas. Mol Vis. 2010;16:1373-1381. 
15. Saunier S, Salomon R, Antignac C. Nephronophthisis. Curr Opin Genet Dev. 2005;15(3):324-331.

16. Hildebrandt F, Zhou W. Nephronophthisis-associated ciliopathies. J Am Soc Nephrol. 2007;18(6):1855-1871.

17. Cai Y, Somlo S. Too much of a good thing: does Nek8 link polycystic kidney disease and nephronophthisis? J Am Soc Nephrol. 2008; 19(3):418-420.

18. Otto EA, Trapp ML, Schultheiss UT, Helou J, Quarmby LM, Hildebrandt F. NEK8 mutations affect ciliary and centrosomal localization and may cause nephronophthisis. J Am Soc Nephrol. 2008;19(3):587-592.

19. Zhou W, Dai J, Attanasio M, Hildebrandt F. Nephrocystin-3 is required for ciliary function in zebrafish embryos. Am J Physiol Renal Physiol. 2010;299(1):F55-F62.

20. Burckle C, Gaude HM, Vesque C, et al. Control of the Wnt pathways by nephrocystin-4 is required for morphogenesis of the zebrafish pronephros. Hum Mol Genet. 2011;20(13):2611-2627.

21. Hurd TW, Hildebrandt F. Mechanisms of nephronophthisis and related ciliopathies. Nephron Exp Nephrol. 2011;118(1):e9-e14.

22. Wolf MT, Hildebrandt F. Nephronophthisis. Pediatr Nephrol. 2011; 26(2):181-194.

23. Hildebrandt F, Attanasio M, Otto E. Nephronophthisis: disease mechanisms of a ciliopathy. J Am Soc Nephrol. 2009;20(1):23-35.

24. Hassounah NB, Bunch TA, McDermott KM. Molecular pathways: the role of primary cilia in cancer progression and therapeutics with a focus on Hedgehog signaling. Clin Cancer Res. 2012;18(9):2429-2435.

25. Pan J, Seeger-Nukpezah T, Golemis EA. The role of the cilium in normal and abnormal cell cycles: emphasis on renal cystic pathologies. Cell Mol Life Sci. 2012:1-26.

26. Chen JS, Huang XH, Wang Q, et al. Sonic Hedgehog signaling pathway induces cell migration and invasion through focal adhesion kinase/AKT signaling-mediated activation of matrix metalloproteinase (MMP)-2 and MMP-9 in liver cancer. Carcinogenesis. 2013;34(1):10-19.

27. Mill P, Lockhart PJ, Fitzpatrick E, et al. Human and mouse mutations in WDR35 cause short-rib polydactyly syndromes due to abnormal ciliogenesis. Am J Hum Genet. 2011;88(4):508-515.

28. Mahjoub MR, Stearns T. Supernumerary centrosomes nucleate extra cilia and compromise primary cilium signaling. Curr Biol. 2012;22(17): $1628-1634$.

29. Guay-Woodford LM. Murine models of polycystic kidney disease: molecular and therapeutic insights. Am J Physiol Renal Physiol. 2003;285(6):F1034-F1049.

30. Wilson PD. Mouse models of polycystic kidney disease. Curr Top Dev Biol. 2008;84:311-350.

31. Woollard JR, Punyashtiti R, Richardson S, et al. A mouse model of autosomal recessive polycystic kidney disease with biliary duct and proximal tubule dilatation. Kidney Int. 2007;72(3):328-336.

32. Gretz N, Kranzlin B, Pey R, et al. Rat models of autosomal dominant polycystic kidney disease. Nephrol Dial Transplant. 1996;11 Suppl 6: 46-51.

33. Harris PC, Rossetti S. Molecular genetics of autosomal recessive polycystic kidney disease. Mol Genet Metab. 2004;81(2):75-85.

34. Lager DJ, Qian Q, Bengal RJ, Ishibashi M, Torres VE. The pck rat: a new model that resembles human autosomal dominant polycystic kidney and liver disease. Kidney Int. 2001;59(1):126-136.

35. Phillips JK, Hopwood D, Loxley RA, et al. Temporal relationship between renal cyst development, hypertension and cardiac hypertrophy in a new rat model of autosomal recessive polycystic kidney disease. Kidney Blood Press Res. 2007;30(3):129-144.

36. O’Meara CC, Hoffman M, Sweeney WE Jr, et al. Role of genetic modifiers in an orthologous rat model of ARPKD. Physiol Genomics. 2012;44(15):741-753.

37. Kuida S, Beier DR. Genetic localization of interacting modifiers affecting severity in a murine model of polycystic kidney disease. Genome Res. 2000;10(1):49-54.

38. Woo DD, Nguyen DK, Khatibi N, Olsen P. Genetic identification of two major modifier loci of polycystic kidney disease progression in pcy mice. J Clin Invest. 1997;100(8):1934-1940.
39. Gong Y, Ma Z, Patel V, et al. HNF-1beta regulates transcription of the PKD modifier gene Kif12. J Am Soc Nephrol. 2009;20(1):41-47.

40. Davis EE, Zhang Q, Liu Q, et al. TTC21B contributes both causal and modifying alleles across the ciliopathy spectrum. Nat Genet. 2011;43(3):189-196.

41. Gate D, Danielpour M, Levy R, Breunig JJ, Town T. Basic biology and mechanisms of neural ciliogenesis and the B9 family. Mol Neurobiol. 2012;45(3):564-570.

42. Paprocka J, Jamroz E. Joubert syndrome and related disorders. Neurol Neurochir Pol. 2012;46(4):379-383.

43. Liu X, Wang S, Wang Y, Wei S. Genetic analysis and molecular mapping of a nuclear recessive male sterility gene, $\mathrm{ms} 91(\mathrm{t})$, in rice. Genome. 2007;50(9):796-801.

44. Tezuka K, Miyadate H, Katou K, et al. A single recessive gene controls cadmium translocation in the cadmium hyperaccumulating rice cultivar Cho-Ko-Koku. Theor Appl Genet. 2010;120(6):1175-1182.

45. Zhang J, Wu M, Wang S, Shah JV, Wilson PD, Zhou J. Polycystic kidney disease protein fibrocystin localizes to the mitotic spindle and regulates spindle bipolarity. Hum Mol Genet. 2010;19(17): 3306-3319.

46. Ronquillo CC, Bernstein PS, Baehr W. Senior-Loken syndrome: a syndromic form of retinal dystrophy associated with nephronophthisis. Vision Res. 2012;75:88-97.

47. Benzing T, Schermer B. Clinical spectrum and pathogenesis of nephronophthisis. Curr Opin Nephrol Hypertens. 2012;21(3):272-278.

48. Fain PR, McFann KK, Taylor MR, et al. Modifier genes play a significant role in the phenotypic expression of PKD1. Kidney Int. 2005;67(4):1256-1267.

49. Torres VE, Sweeney WE Jr, Wang X, et al. Epidermal growth factor receptor tyrosine kinase inhibition is not protective in PCK rats. Kidney Int. 2004;66(5):1766-1773.

50. Rohatgi R, Battini L, Kim P, et al. Mechanoregulation of intracellular $\mathrm{Ca} 2+$ in human autosomal recessive polycystic kidney disease cyst-lining renal epithelial cells. Am J Physiol Renal Physiol. 2008;294(4):F890-F899.

51. Nauta J, Goedbloed MA, Herck HV, et al. New rat model that phenotypically resembles autosomal recessive polycystic kidney disease. J Am Soc Nephrol. 2000;11(12):2272-2284.

52. Davis EE, Katsanis N. The ciliopathies: a transitional model into systems biology of human genetic disease. Curr Opin Genet Dev. 2012;22(3):290-303.

53. Fall PJ, Prisant LM. Polycystic kidney disease. J Clin Hypertens (Greenwich). 2005;7(10):617-619, 625.

54. Gabow PA, Chapman AB, Johnson AM, et al. Renal structure and hypertension in autosomal dominant polycystic kidney disease. Kidney Int. 1990;38(6):1177-1180.

55. Chapman AB, Johnson A, Gabow PA, Schrier RW. The renin-angiotensin-aldosterone system and autosomal dominant polycystic kidney disease. N Engl J Med. 1990;323(16):1091-1096.

56. King JN, Tasker S, Gunn-Moore DA, Strehlau G. Prognostic factors in cats with chronic kidney disease. $J$ Vet Intern Med. 2007;21(5):906-916.

57. Kuwahara Y, Ohba Y, Kitoh K, Kuwahara N, Kitagawa H. Association of laboratory data and death within one month in cats with chronic renal failure. J Small Anim Pract. 2006;47(8):446-450.

58. Jain S, Kamat D. Evaluation of microcytic anemia. Clin Pediatr (Phila). 2009;48(1):7-13.

59. Guay-Woodford LM, Bryda EC, Christine B, et al. Evidence that two phenotypically distinct mouse PKD mutations, bpk and jcpk, are allelic. Kidney Int. 1996;50(4):1158-1165.

60. Upadhya P, Churchill G, Birkenmeier EH, Barker JE, Frankel WN. Genetic modifiers of polycystic kidney disease in intersubspecific KAT2J mutants. Genomics. 1999;58(2):129-137.

61. Bihoreau MT, Megel N, Brown JH, et al. Characterization of a major modifier locus for polycystic kidney disease (Modpkdr1) in the Han:SPRD(cy/+) rat in a region conserved with a mouse modifier locus for Alport syndrome. Hum Mol Genet. 2002;11(18):2165-2173. 


\section{Publish your work in this journal}

The International Journal of Nephrology and Renovascular Disease is an international, peer-reviewed open-access journal focusing on the pathophysiology of the kidney and vascular supply. Epidemiology, screening, diagnosis, and treatment interventions are covered as well as basic science, biochemical and immunological studies. The journal welcomes

original research, clinical studies, reviews \& evaluations, expert opinion and commentary, case reports and extended reports. The manuscript management system is completely online and includes a very quick and fair peerreview system, which is all easy to use. Visit http://www.dovepress.com/ testimonials.php to read real quotes from published authors.

Submit your manuscript here: http://www.dovepress.com/international-journal-of-nephrology-and-renovascular-disease-journal 